\title{
The Extract of Glycyrrhiza uralensis Fisch Induces Apoptosis in MGC-803 Cells and its Molecular Mechanisms
}

\author{
Jing Ma', Wenlie Peng ${ }^{1}$, Dong Liang ${ }^{1}$, Naiyang Fu', Daben Pang ${ }^{2}$ and Anlong Xu ${ }^{1}$ \\ 'Department of Biochemistry, Center for Biopharmaceutical Research and State key Laboratory for Biocontrol, College of Life \\ Science, Zhongshan University, Guangzhou 510275, P.R. China; \\ ${ }^{2}$ Institute of Fundamental Theory Research, China Academy of Chinese Traditional Medicine, Beijing 100700, P.R. China \\ (Received 20 April 2000; and accepted 15 June 2000)
}

\begin{abstract}
Glycyrrhiza uralensis Fisch has been used as an antidote, anti-inflammatory, demulcent and elixir folk medicine for generations in China. The present study demonstrates for the first time that the extract of glycyrrhiza uralensis Fisch (EGUF) induces apoptosis in human gastric cancer cell line MGC-803 as determined by fluorescence microscope, flow cytometry, DNA agarose gel electrophoresis and TUNEL assay. We also report here the up-regulation of two oncogenes, $c-m y c$ and $c$-jun, in the treated cells using RT-PCR and immunohistochemistry assay. By flow cytometry, measurements with the $\mathrm{Ca}^{2+}$-sensitive dye Fluo-3-AM revealed significant enhancement of intracellular $\mathrm{Ca}^{2+}$ content in a dose-dependent manner following the treatment with EGUF. Increased activity of protein kinase C (PKC) in MGC-803 exposed to EGUF was also investigated. In addition, pretreatment of MGC-803 cells with staurosporine (a PKC inhibitor) or PMA (a PKC activator) significantly suppressed or boosted apoptosis induced by EGUF respectively. These findings suggest that glycyrrhiza uralensis Fisch may be a potential, natural apoptosis-inducing agent for gastric cancer therapy and the increase of $\mathrm{Ca}^{2+}$-dependent PKC activity plays a critical role in the apoptotic process induced by EGUF.
\end{abstract}

Apoptosis, or programmed cell death, is a biological event that is biochemically and morphologically distinct from cellular necrosis. Under strict genetic regulation, apoptosis is an

Correspondence to: $\mathrm{Dr}$ Anlong $\mathrm{Xu}$, at above address. Tel. 086-020-84113655; Fax: 086-020-84038377; Email: 1s36@zsu.edu.cn

Abbreviations: EGUF, the extract of Glycyrrhiza uralensis Fisch; TUNEL, terminal transferasemediated dUTP-digoxigenin Nick End Labeling; PKC, protein kinase C; TCM, traditional Chinese medicine; PI, propidium iodide; AP, alkaline phosphatase; ABC, Avidin-biotin-complex; Fluo-3-AM, Fluo-3-acetoxymethyl ester; GL, glycyrrhizin; DMBA, 7, 12-dimethyl-benz [a] anthracene; TPA, 12-O-tetradcanoylphorbol-13-acetate; MNNG, $N$ methyl- $N$ 1-nitro- $N$-nitrosoguanidine; PBS, phosphate buffered saline; $\left[\mathrm{Ca}^{2+}\right]_{\text {, }}$, intracellular $\mathrm{Ca}^{2+}$. active cellular death process characterized by distinctive morphological changes including chromatin condensation, cell shrinkage, DNA fragmentation, plasma membrane blebbing and the formation of membrane-bound apoptotic bodies (13). There is a growing body of evidence that the possible mechanisms of action of various anticancer drugs in current use are related to the ability of these drugs to induce apoptosis in target tumor cells (11). Apoptotic cells are recognized and engulfed by macrophages so that the cells are removed without induction of inflammation. Therefore, apoptosis-inducing agent specific for tumor cells may be expected to be ideal anticancer drugs and the induction of apoptosis is a new target for anti-cancer drug discovery.

Traditional Chinese Medicine (TCM) has been used in cancer therapy in China for thousands of 
years with well-documented therapeutic efficacy, although the underlying mechanisms in most cases remain elusive. Recently, more and more attention has been focused on apoptosis as one of the anti-neoplastic mechanisms of TCM. Bufalin specifically induced apoptosis in human leukemia cells by altering the expression of $c-m y c$ and $b c l-2$, both genes are known to play important roles in apoptosis (16); Radix Salivae Miltrorrhizae prompted fibroblast in culture of kidney with Lupus Nephritis (LN) to apoptosis, possibly through the hyper-expression of $c$-myc (30); Tetrandrine and berbamine inhibited the proliferation of HL-60 cells via induction of apoptosis (8); Sodium artesunate induced human liver cancer cell line BEL-7402 to apoptosis by p53independent pathway (31); Induction of cell apoptosis might be one of the mechanism of the therapeutic effect of $\mathrm{As}_{2} \mathrm{O}_{3}(6)$; Camptothecin and taxol are anticancer drugs that effectively induce apoptosis in many tumor cells $(4,14,26)$.

Following the new strategy of anti-cancer drug screening proposed by National Cancer Institute (NCI, USA), our laboratory has recently established an in vitro fast system for screening novel anti-neoplastic TCM based on their ability to induce tumor cells to apoptosis. We have found that glycyrrhiza uralensis, an extensively used TCM for generations, is an excellent apoptosisinducing agent for human gastric cancer cell line MGC-803. In this paper, we report this new function of glycyrrhiza uralensis and the possible molecular mechanism associated.

\section{MATERIALS AND METHODS}

Preparation of EGUF. Glycyrrhiza uralensis. Fisch was extracted with water/ethanol $(1: 1)$ by heating under reflux at $80^{\circ} \mathrm{C}$ and the resulting extract was spray-dried to obtain extract powder. The extract powder was weighed and dissolved in PBS at the desired concentration. The solution was centrifuged to remove insoluble ingredients and then the supernatant was passed through 0.22 $\mu \mathrm{m}$ filters for sterilization.

Cell culture and exposure to EGUF. Human gastric cancer cell line MGC-803 was obtained from the Institute of Biophysics, Chinese Academy of Sciences. Cells were cultured in RPMI 1640 (GIBCO-BRL, Life Sciences) supplemented with 10\% heat inactivated fetal bovine serum (Chuanye Company, Tianjing, China), $100 \mathrm{U} /$
$\mathrm{mL}$ of penicillin and $100 \mu \mathrm{L} / \mathrm{mL}$ of streptomycin at $37^{\circ} \mathrm{C}$ in $5 \% \mathrm{CO}_{2}$. Cells in $\log$ phase growth were treated with $0.5 \mathrm{mg} / \mathrm{mL}, 0.75 \mathrm{mg} / \mathrm{mL}, 1.0 \mathrm{mg} / \mathrm{mL}$ or $1.5 \mathrm{mg} / \mathrm{mL}$ of EGUF respectively for different time.

Nuclear staining and morphology. Cells were harvested by centrifugation and suspended in fresh culture medium and then stained with propidium iodide (PI, $50 \mu \mathrm{g} / \mathrm{mL}$ ) and Hoechst33342 $(10 \mu \mathrm{g} / \mathrm{mL})$ (Molecular Probes, USA). The cell suspension was incubated at $37^{\circ} \mathrm{C}$ for 30 min and centrifuged to remove most of the supernatant. Pellet was suspended in the remaining culture medium and smeared for fluorescence microscope (Olympus, Japan).

Flow cytometry. Approximately $1 \times 10^{6}$ cells were collected, washed twice with PBS, and then fixed overnight in $70 \%$ ethanol. After RNase A digestion $(60 \mu \mathrm{g} / \mathrm{mL})$ for $30 \mathrm{~min}$ at $37^{\circ} \mathrm{C}$, cells were stained with PI $(50 \mu \mathrm{g} / \mathrm{mL})$ for $30 \mathrm{~min}$ at $4^{\circ} \mathrm{C}$ in dark and analyzed by Flow Cytometry (Coulter EPICS XL, U.S.A.)(Ex 488 nm; Em 620 nm).

Analysis of DNA fragmentation. Analysis of DNA fragmentation in MGC-803 cells was performed by the method of Smith et al (24). Cells were collected by centrifugation and suspended in denaturing solution $(100 \mu \mathrm{g} / \mathrm{mL}$ proteinase $\mathrm{K}, 10$ $\mathrm{mmol} / \mathrm{L}$ Tris-HCL, $\mathrm{pH} 8.0,15 \mathrm{mmol} / \mathrm{L} \mathrm{NaCl}, 10$ $\mathrm{mmol} / \mathrm{L}$ EDTA, pH 8.0, 0.4\% SDS) for $12-24 \mathrm{~h}$ at $37^{\circ} \mathrm{C}$. Total DNA was isolated by phenol/chloroform extraction and ethanol precipitation. DNA $(8 \mu \mathrm{g})$ The collected was electrophoresed in $1.5 \%$ agarose gel and visualized by UV illumination after staining with $0.5 \mu \mathrm{g} / \mathrm{mL}$ ethidium bromide.

End labeling of cells (TUNEL). Cells were fixed with freshly prepared paraformaldehyde solution and permeabilized. DNA fragments were endlabeled with modified nucleotides using exogenous terminal transferase. The incorporated nucleotides were visualized with a secondary detection system containing alkaline phosphatase (AP) reporter molecule (Boehringer Mannheim, USA). Liquid BCIP/NBT (Maixin Company, China) was used as specific substrate for color displaying. Nuclear fast red solution was used for counterstaining.

Immunohistochemistry assay. The cells cultured on plastic coverslip were fixed with cold acetone, 
transferred to $\mathrm{PBS}$ and stored at $4^{\circ} \mathrm{C}$. Prior to $\mathrm{ABC}$ (Avidin-biotin-complex) treatment, the cells were incubated in fresh solution of $0.3 \% \mathrm{H}_{2} \mathrm{O}_{2}$ in methanol for $30 \mathrm{~min}$ at room temperature to inhibit endogenous peroxidase activity, blocked by $1.5 \%$ serum and then mixed with either $c-j u n$ mouse polyclonal antibody $(1: 60)$ or $c-m y c$ mouse monoclonal antibody $(1: 60)$ (Santa Cruz, USA). After washing by PBS, the cells were incubated with biotinylated anti-mouse $\operatorname{IgG}(1$ : 100 ) and then with the avidin-biotin complex solution (Vecter Lab, USA). DAB $/ \mathrm{H}_{2} \mathrm{O}_{2}$ (Vecter Lab, USA) was used for development. Finally the cells were counterstained with Mayer's hematoxylin solution.

Semi-quantitative reverse transcriptase $P C R$ analysis. Total RNA was extracted from each sample by TRIZOL reagent (GIBCO-BRL). The cDNA was synthesized by Reverse Transcription System (Promega) starting from $2 \mu \mathrm{g}$ of total RNA. PCR amplification was performed in 40 $\mu \mathrm{L}$ of $1 \times$ buffer containing $0.25 \mathrm{mM} \mathrm{dNTP}, 1.5$ $\mathrm{mM} \mathrm{MgCl} 2,2$ units of Taq DNA polymerase, 4 $\mu \mathrm{L}$ of each RT product and $25 \mathrm{pmoL}$ of each primer (synthesized by Beijing SBS Biotechnology Company), GAPDH was also amplified as an internal control.

Primers used for amplification of c-jun: 5'GGAAACGACCTTCTATGACGATGCCCTCAA and 5'-GAACCCCTCCTGCTCATCTGTCACGTTCTT.

Primers used for amplification of c-myc: 5'CTGGCAAA AGGTCAGAGTCTGGATCACCTT and 5'-TGTCTCAGGACTCTGACACTGTCCAACTTG.

PCR reaction was allowed to proceed for 30 cycles, each cycle consisting of $60 \mathrm{~s}$ at $94^{\circ} \mathrm{C}, 60 \mathrm{~s}$ at $60^{\circ} \mathrm{C}$ and $90 \mathrm{~s}$ of polymerization at $72^{\circ} \mathrm{C}$ and finally a $7 \mathrm{~min}$ extension at $72^{\circ} \mathrm{C} .5 \mu \mathrm{L}$ aliquots of the PCR reaction were separated in a $1.2 \%$ agarose gel. The bands on the gel were scanned vertically by densitometry (Bio-Rad, USA) and analyzed by Bio-Rad Multi-Analyst Version 1.1. Densitometric intensity of $c-j u n$ or $c-m y c$ was normalized against that of GAPDH.

Intracellular $\mathrm{Ca}^{2+}$ determination. The level of intracellular $\mathrm{Ca}^{2+}$ was determined by flow cytometry after staining with Fluo-3acetoxymethyl ester (Flou-3-AM, Molecular Probes) as previously described (19). Cells were collected by centrifugation at the end of the incu- bation time, suspended in $200 \mu \mathrm{L}$ fresh culture medium and stained with Flou-3-AM $(5 \mu \mathrm{mol} / \mathrm{L})$ for $40 \mathrm{~min}$ at $37^{\circ} \mathrm{C}$. After incubation, cells were washed twice in cold PBS, resuspended at a concentration of $1 \times 10^{6}$ cells per $\mathrm{mL}$ in PBS and analyzed by flow cytometry (Ex $488 \mathrm{~nm}$; Em 530 $\mathrm{nm})$.

Activity of $P K C$. PKC activity were detected using Protein Kinase $C$ Assay System kit (GIBCO-BRL, USA). Cell suspension was centrifuged and the supernatant was replaced immediately with PBS. The cells were washed twice with PBS and counted. After centrifugation, the cells were resuspended in extract buffer and homogenized 10-15 strokes on ice in a pre-cooled dounce homogenizer. Cellular debris was removed by centrifuging and the supernatant was saved on ice. Assay and control tubes were set up according to the protocol of the kit. After the tubes were incubated at room temperature for 20 min to allow inhibitor to bind, P32/Substrate was added for $5 \mathrm{~min}$ at $30^{\circ} \mathrm{C}$. $25 \mu \mathrm{L}$ from each tube was spotted onto the corresponding phosphocellulose disc. After twice acid wash and twice $\mathrm{H}_{2} \mathrm{O}$ wash, peptide incorporated ${ }^{32} \mathrm{P}$ was counted using liquid scintillation counter.

\section{RESULTS}

\section{Morphological changes}

After treatment with the different concentration of EGUF for $20 \mathrm{~h}$, the cells with various morphological changes compatible with apoptosis (chromatin condensation, nuclear framentation, appearance of apoptotic bodies) were observed. Under treatment with low concentration of EGUF $(0.5 \mathrm{mg} / \mathrm{mL})$, most of apoptotic cells were in the early phase of apoptosis: condensation of nuclear chromatin appeared, forming uniformly dark, crescentic masses which migrated towords the nuclear envelop (Fig. 1B), or forming some blocks of chromatin condensation in the inner leaflet of the nuclear membrane (Fig. 1C); under treatment with $0.75 \mathrm{mg} / \mathrm{mL}$ EGUF, the morphological changes in the cells were mainly characterized with the middle-phase apoptosis: chromatin condensation began to appear in the cytosol by nucleus blebbing (9) (Fig. 1D); under treatment with $1.0 \mathrm{mg} / \mathrm{mL}$ EGUF, membranebound vesicles (apoptotic bodies) were eventually formed by membrane blebbing, and the cells reached the later phase of apoptosis (Fig. 1E); 
however, when the concentration of glycyrrhiza uralensis Fisch was further increased $(1.5 \mathrm{mg}$ / $\mathrm{mL}$ ), the integrity of the plasma membrane was compromised and the apoptotic cells turned to 'second necrosis' associated with PI staining (Fig. $1 \mathrm{~F})$.

\section{The percentage of cells undergoing apoptosis}

Flow cytometry can identify and quantify apoptotic cells based on DNA content analysis of ethanol-fixed and permeabilized cells following extraction of the degraded low MW DNA. When a population of cells which contains cells undergoing apoptosis are stained with a DNAfluorochrome PI, an additional DNA peak (usually called 'sub-G $G_{1}$ peak' or 'apoptotic peak') may be observed. Flow cytometric measurement of DNA content demonstrated exposure of exponentially growing MGC-803 cells to EGUF led to the presence of cells with typical apoptosis characteristic. Moreover, the percentage of cells undergoing apoptosis in response to EGUFtreatment was enhanced with the increase of the concentration of EGUF and the prolongation of incubation time with EGUF.

\section{The appearance of 'DNA ladder' on agarose gel}

The biochemical hallmark of apoptosis is the DNA fragmentation into multiples of $180-200 \mathrm{bp}$ in length, generating on DNA electrophoresis gel the typical 'DNA ladder' pattern. When MGC803 cells were respectively treated with $0.5 \mathrm{mg} /$
$\mathrm{mL}$ and $1.5 \mathrm{mg} / \mathrm{mL}$ of EGUF for $16 \mathrm{~h}$, the obvious DNA ladder was observed only in the cells treated with $1.5 \mathrm{mg} / \mathrm{mL}$ EGUF(data not shown). To determine the kinetics of appearance of DNA ladder fragmentation, the cells were harvested at various times under treatment with $1.5 \mathrm{mg} / \mathrm{mL}$ EGUF. As shown in Fig. 4, DNA fragmentation increased with the prolongation of the incubation time.

\section{TUNEL assay}

TUNEL assay is another method of assessment of apoptosis, which was based on the detection of

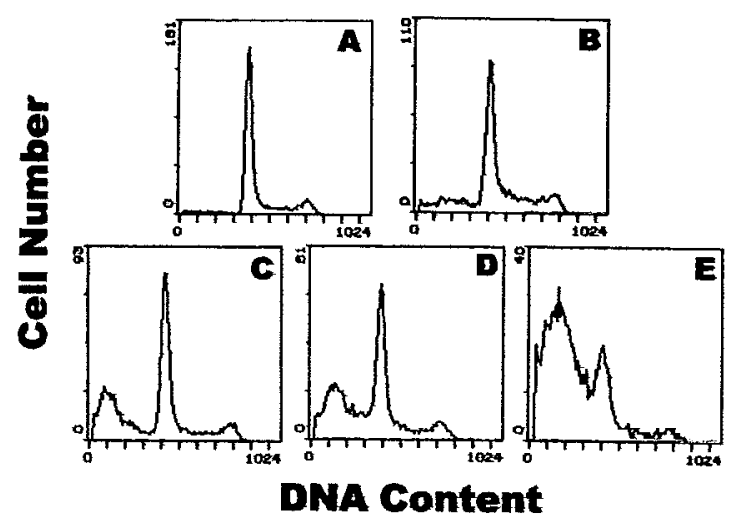

Fig. 2 FCM analysis of apoptosis induced by different concentration of EGUF for $23 \mathrm{~h}$. (A) Control, $2.8 \% \mathrm{MGC}-803$ cells were treated with $0.5 \mathrm{mg} / \mathrm{mL}$, $0.75 \mathrm{mg} / \mathrm{mL}, 1.0 \mathrm{mg} / \mathrm{mL}$ or $1.5 \mathrm{mg} / \mathrm{mL}$ EGUF for 23 $\mathrm{h}$, the percentage of apoptosis was $23.7 \%$ (B), $35.7 \%$ (C), 47.9\% (D), 68.7\% (E) respectively.

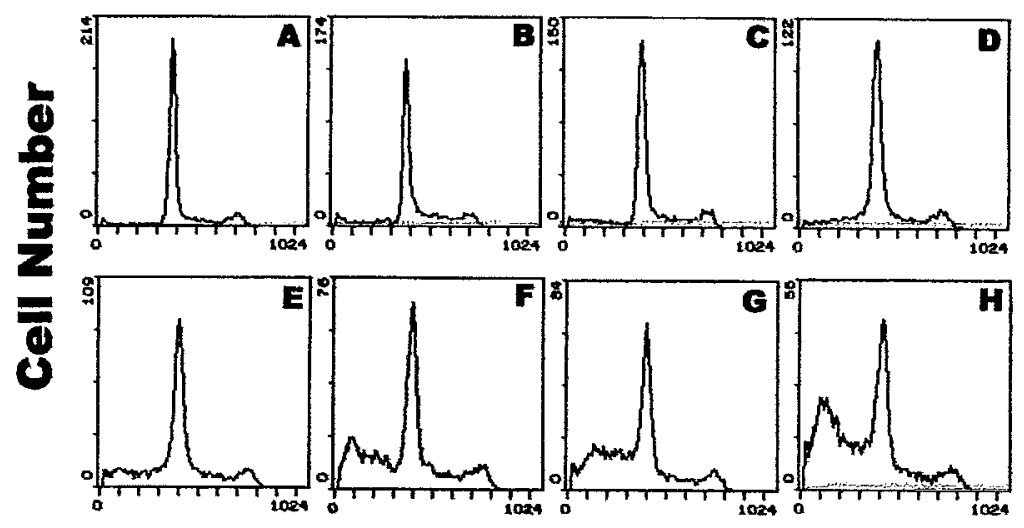

DNA Content

Fig. 3 FCM analysis of apoptosis induced by $1.0 \mathrm{mg} / \mathrm{mL}$ EGUF for different time. (A) Control, 4.6\% (B-H) MGC-803 cells were treated with $1.0 \mathrm{mg} / \mathrm{mL}$ EGUF for $1,4,7,11,15,19,23 \mathrm{~h}$, the percentage of apoptosis was $9.8 \%(B), 12.0 \%(C), 15.4 \%$ (D), 22.5\% (E), 39.1\% (F), 44.3\% (G), 52.2\% (H), respectively. 


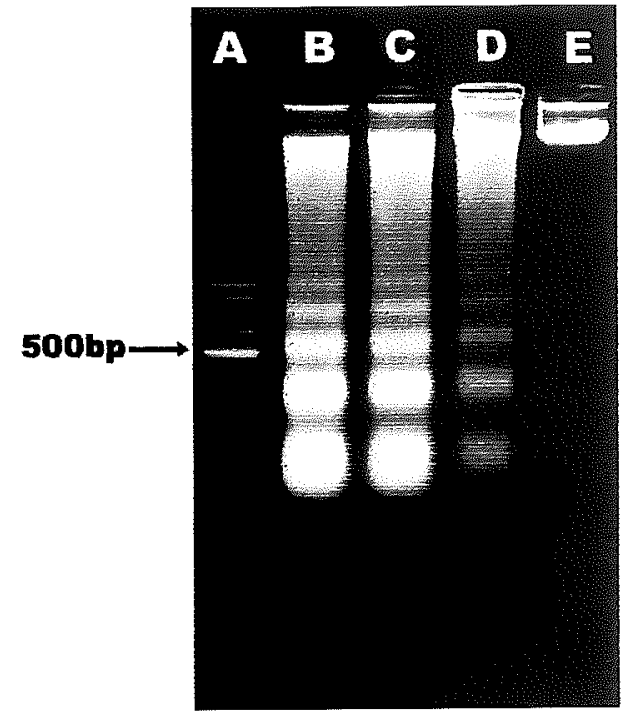

Fig. 4 Agarose gel electrophoresis of DNA from cells treated with $1.5 \mathrm{mg} / \mathrm{mL}$ EGUF for various times. (A) 100 bp DNA marker. (B)-(D) Cells were harvested after treated for $20 \mathrm{~h}, 16 \mathrm{~h}$ and $12 \mathrm{~h}$ respectively. (E) Control.

DNA strand breaks in individual cells at the very early stage of the apoptosis. The cells stained black in TUNEL assay were apoptotic cells as shown in Fig. 5B.

\section{Up-expression of two oncogenes}

We examined the effects of EGUF on the expression of two oncogenes, namely, $c-j u n$ and $c-m y c$, in MGC-803 cells at RNA and protein level. Fig. 6 shows the results of immunohistochemistry analysis of $c$-jun and $c-m y c$ in MGC-803 cells after treatment with $0.75 \mathrm{mg} / \mathrm{mL}$ EGUF for $15 \mathrm{~h}$. The brown particles inside the nuclear implicated protein expression, the darker the color, the higher the protein expression. It indicated that the protein expression of $c-m y c, c-j u n$ was low in control cells and was greatly elevated after treatment with EGUF. The extent of the elevation was in the order of $c-m y c<c-j u n$, which was the same case in the result of RT-PCR (Fig. 7). Densitometric measurement showed that the upregulation of $c$-jun $(0.539 / 0.052=10.360)$ was about three-fold of that of $c-m y c(0.887 / 0.284=3.123)$.

\section{Increase of intracellular $\mathrm{Ca}^{2+}$ concentration}

The biochemical pathways that lead to cell death by apoptosis are complex, but growing evidence suggests that the increase in $\left[\mathrm{Ca}^{2+}\right]_{i}$ plays a key role in apoptosis. After MGC-803 cells were exposed to various concentration of EGUF for $7 \mathrm{~h},\left[\mathrm{Ca}^{2+}\right]_{\mathrm{i}}$ was elevated in dose-dependent manner.

PKC modulates the apoptosis induced by $E G U F$

After treatment with $0.75 \mathrm{mg} / \mathrm{mL}$ EGUF, PKC activity was observed to increase using PKC assay system kit and the increase was more obvious in the early hours. PKC possessed a positive role in the experiment, which was demonstrated again by inhibition or activation of PKC. The cells were pre-treated with PKC inhibitor (staurosporine or $\mathrm{H}-7$ ) or activator (PMA) for $60 \mathrm{~min}$ prior to the addition of EGUF. As shown in Fig. 10, there was a more pronounced percentage of apoptosis in cells pre-treated with PMA than in those without the pre-treatment $(P<0.01)$, while PMA alone couldn't induce apoptosis $(P>0.05)$. Pretreatment of staurosporine largely decreased the percentage of apoptosis $(P<0.01)$, while $\mathrm{H}-7$ has no significant effect $(P>0.05)$ None of the inhibitors alone significantly affect the cells $(P>$ $0.05)$.

\section{DISCUSSION}

Natural products have been excellent and reliable sources for the development of new drugs. Up to $60 \%$ of the anticancer drugs over the past 10 years, for example, have their source in tropical rain forests. TCM, as an important part of natural products in the world, should play a pivotal role in the discovery of new drugs, especially new anticancer drugs. To find new anti-cancer substances from TCM, simple and fast assay system are needed to facilitate the processing of a great number of samples. Using in vitro experimental system of apoptosis developed in our laboratory, we have screened various TCM for anti-cancer effects.

In Chinese Medicine, Glycyrrhiza has been mainly applied in anti-inflammation, anti-virus, antitoxin, anti-gastric ulcer. Recently, in vitro and in vivo experiments have shown that this herb also displays an anticancer activity. Water extract of licorice protected against benzopyrene- and $N$-nitrosodiethylamine-induced lung and forestomach tumorigenesis in $\mathrm{A} / \mathbf{J}$ mice (28). Glycyrrhetinic acid was found to protect the 

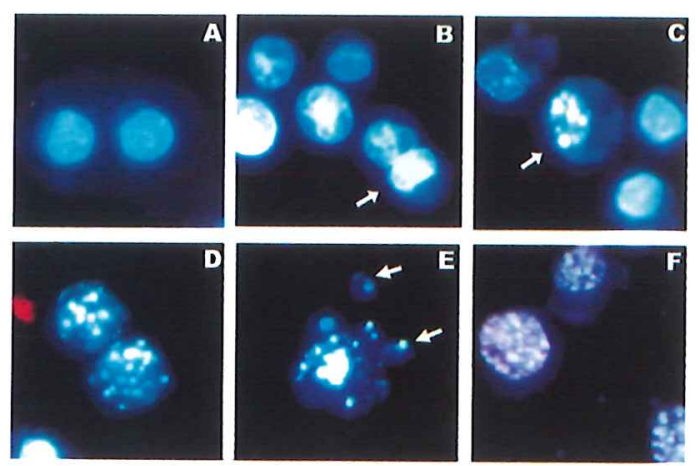

Fig. 1 Fluorescence photomicrographs of cells stained with Hoechst 33342 and PI after treated with EGUF. (A) Control (B) Chromatin condensation as a whole (C). Chromatin condensation in the nucleus (D) Chromatin condensation in the cytosol (E) Formation of apoptotic body (F) Permeability change of apoptotic cells' membrane. $(40 \times 10)$.

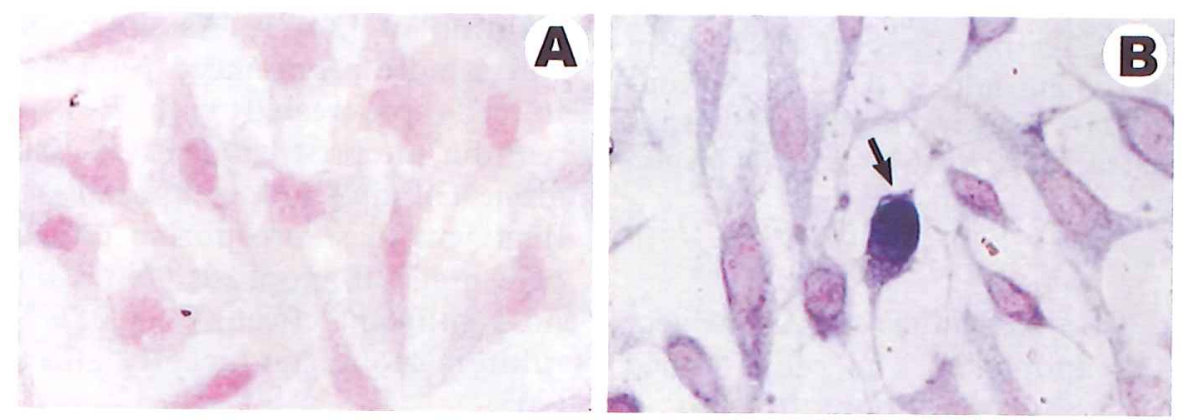

Fig. 5 In situ detection of apoptotic cells under treatment with EGUF. A. Control B. The cells were treated with $0.75 \mathrm{mg} / \mathrm{mL}$ EGUF for $15 \mathrm{~h}$. $(40 \times 10)$
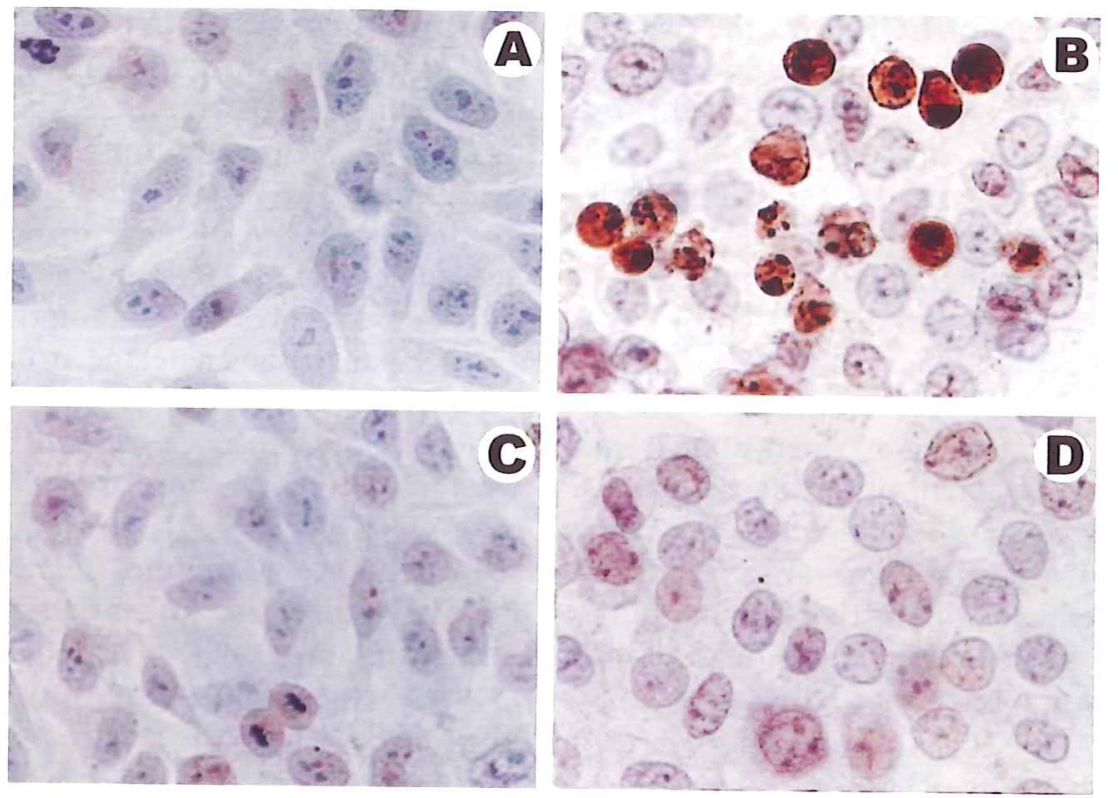

Fig. 6 Immunohistochemistry analysis of the expression of $c$-jun and $c-m y c$. (A) and (C) $c-j u n$ and $c$-myc in control cells respectively, (B) and (D) $c$-jun and $c$-myc in the cells treated with $0.75 \mathrm{mg} / \mathrm{mL} \mathrm{EGUF} \mathrm{for} 15$ h, respectively. $(40 \times 10)$ 


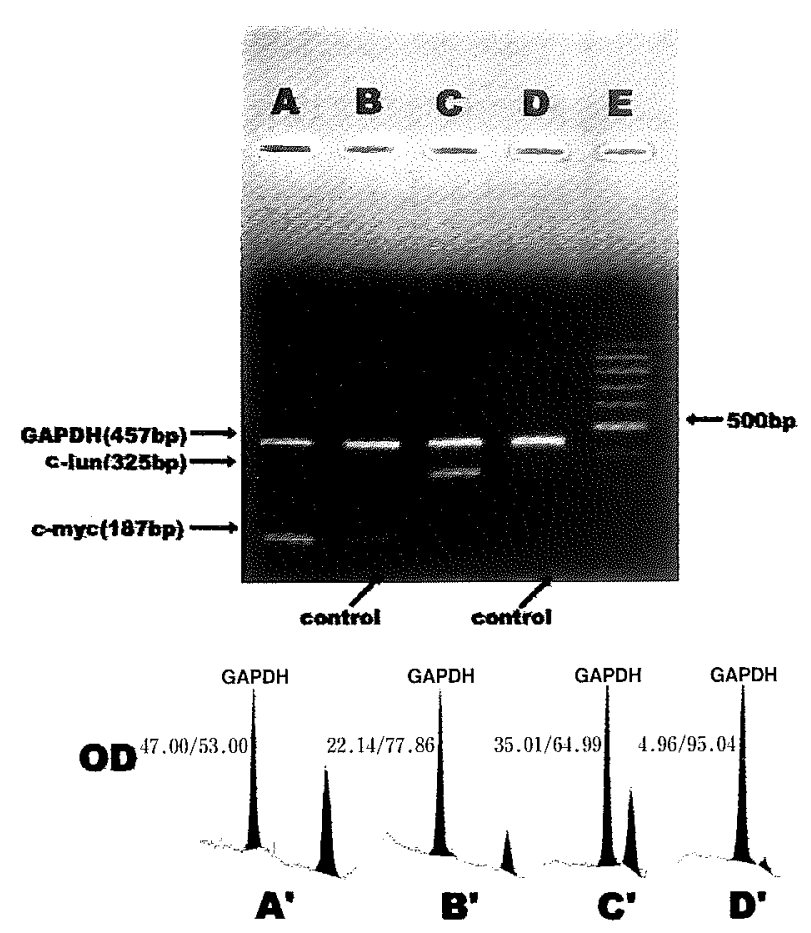

Fig. 7 Results of RT-PCR of $c-j u m$ and $c-m y c$. (A) $c-m y c, 0.75 \mathrm{mg} / \mathrm{mL}, 15 \mathrm{~h}$ (B) $c-m y c$, control (C) $c-j u n, 0.75 \mathrm{mg} / \mathrm{mL}, 15 \mathrm{~h}$ (D) $c$-jun, control (E) 100 bp DNA marker; Interpretation of the RT-PCR data (A') $c-m y c, 0.75 \mathrm{mg} / \mathrm{mL}, 15 \mathrm{~h}$, ratio $=0.887$ (B') $c$ $m y c$, control, ratio $=0.284$ (C') $c-j u n, 0.75 \mathrm{mg} / \mathrm{mL}$, $15 \mathrm{~h}$, ratio $=0.539$ (D') $c$-jum, control, ratio $=0.052$

rapid DNA damage induced by benzo (alpha) pyrene (7). Oral feeding of glycyrrhizin (GL) to Sencar mice resulted in substantial protection against skin tumorigenesis caused by $7,12-$ dimethyl-benz [a] anthracene (DMBA) initiation and 12-O-tetradcanoylphorbol-13-acetate (TPA) promotion (1). Glyrrhiza Uralensis not only exerted strong effects in blocking mutagenesis but also impeded the occurrence of stomach cancer induced by $N$-methyl- $N 1$-nitro- $N$-nitroso-

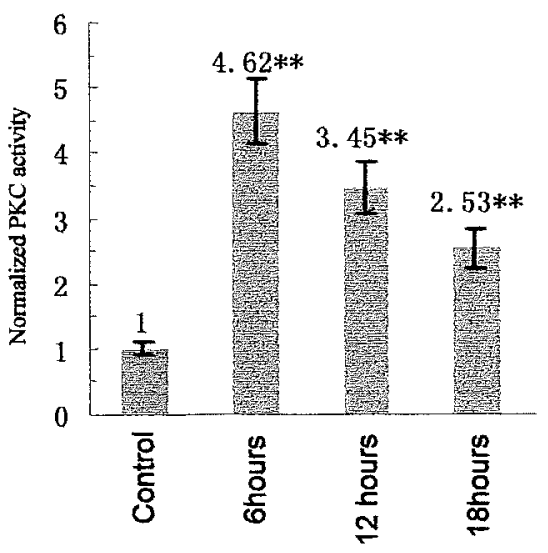

Fig. 9 Increase of PKC activity. PKC activity of MGC-803 exposed to $0.75 \mathrm{mg} / \mathrm{mL}$ EGUF for 6,12 and $18 \mathrm{~h}$ was determined respectively. Data presented are means $\pm S D$ of three independent experiments. Statistical significance with respect to control values for $* * P<0.01$ was determined by $t$-test for unpaired data.

guanidine (MNNG) (22). The present study provided some supportive evidences for the presumption that EGUF induces apoptosis in MGC-803 cell line, i.e., chromatin condensation, apoptotic bodies formation, DNA fragmentation in a ladder pattern, sub- $\mathrm{G}_{1}$ peak appearance in $\mathrm{FCM}$ analysis. To our knowledge, the present paper is for the first time to investigate the anti-cancer activity of glycyrrhiza from the mechanism of apoptosis.

It has been suggested that oncogenes, such as $c$-myc and c-jun might regulate apoptosis in various cells (5). In the present study, upregulation of these two oncogenes were observed in MGC-803 cell line's apoptosis induced by EGUF. The $c$-myc protein is a transcription factor and is involved in the regulation of cell proliferation, differentiation and apoptosis. Many studies demonstrate that the up-regulation

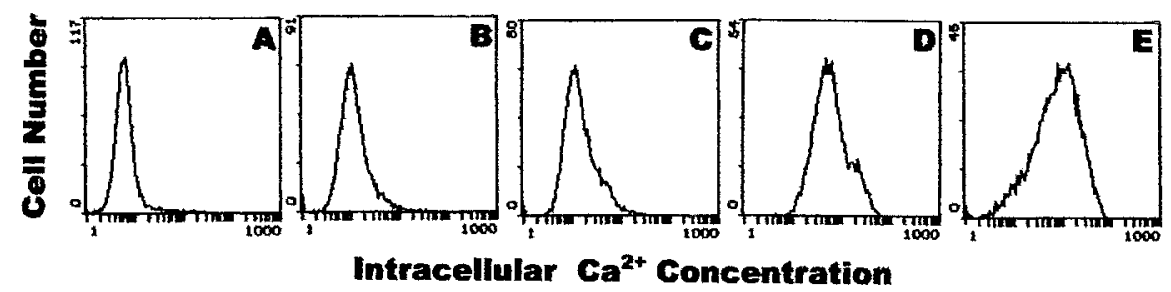

Fig. 8 Increase of $\left[\mathrm{Ca}^{2+}\right]_{\mathrm{i}}$ in MGC-803 cells caused by EGUF. (A) control, mean value of Fluo-3 fluorescence intensity is 1.06 (B) $0.5 \mathrm{mg} / \mathrm{mL}, 1.84$ (C) $0.75 \mathrm{mg} / \mathrm{mL}, 2.28$ (D) $1.0 \mathrm{mg} / \mathrm{mL}, 8.89$ (E) $1.5 \mathrm{mg} / \mathrm{mL}, 12.3$. All were treated for $7 \mathrm{~h}$. Data are representatives of three independent experiments. 


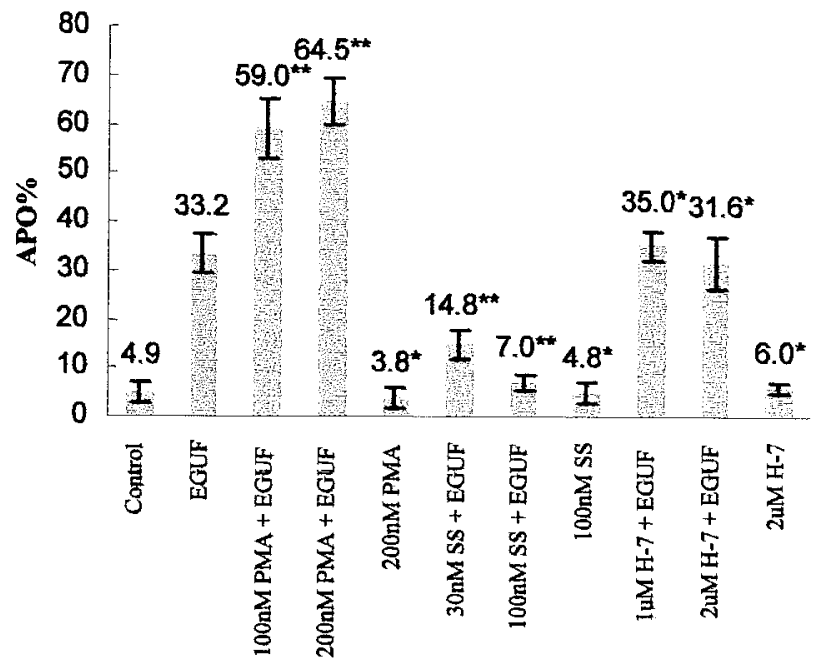

Fig. 10 Effect of activation/inhibition of PKC on apoptosis. MGC-803 cells were preincubated with PMA, staurosporine (SS) or $\mathrm{H}-7$ for $60 \mathrm{~min}$ before exposed to EGUF. The percentage of apoptotic cells was analyzed by FCM after treatment with $0.75 \mathrm{mg}$ / $\mathrm{mL}$ EGUF for $23 \mathrm{~h}$. Data presented are means $+\mathrm{SD}$ of three independent experiments. Statistical significance with respect to control values for $* P>0.05$ and $* * P<0.01$ was determined by $t$-test for unpaired data.

of the $c-m y c$ gene promotes cell proliferation and its down-regulation leads to differentiation (12). However, there are conflicting reports concerning the role of $c-m y c$ on the induction of apoptosis. In some cell types, expression of $c-m y c$ induces apoptosis (3), whereas down-regulation of $c-m y c$ levels in other cells leads to the apoptotic process (2). Evan et al. showed that $c-m y c$ expression causes apoptosis only under conditions of growth factor deprivation (21). c-jun is associated with $c$-fos to form the AP-1 complex (23). AP-1 complex is one of the substrate of PKC, which is very important in the signal transduction of apoptosis (29).

$\mathrm{Ca}^{2+}$ is a ubiquitous intracellular messenger and in many instances of apoptosis alterations of $\mathrm{Ca}^{2+}$ homeostasis are involved. Change of $\left[\mathrm{Ca}^{2+}\right]_{i}$ probably activates downstream reactions other than elicits cell death by itself (20). Several important enzymes have been recognized as $\mathrm{Ca}^{2+}$-sensitive, such as, endonuclease, PKC (15), transglutaminases (10) and calpain (25). PKC, a family of isozymes, is believed to take part in the regulation of apoptosis as a major mediator of $\mathrm{Ca}^{2+}$ signal transduction pathways.
The role of $\mathrm{PKC}$ in the induction of apoptosis has been complicated by conflicting reports. Activation of PKC by exposure to PMA, either alone or in combination with calcium-ionophore, induces apoptosis in lymphoid cells (18). On the other hand, PMA can oppose steroid-induced apoptosis in thymic lymphocytes (17), radiationinduced apoptosis in vitro (27). In our present study, PKC activation accompanyed with $\left[\mathrm{Ca}^{2+}\right]_{i}$ increase induced apoptosis in EGUF-treated cells, and the elevation of $\left[\mathrm{Ca}^{2+}\right]_{i}$ was essential for PMA to promote apoptosis in MGC-803 cell line. From the distinct result of two PKC inhibitors, it is deduced that one kind of isozyme of PKC (specifically inhibited by staurosporine) takes effect on the apoptosis of MGC-803 induced by EGUF.

In order to find the real "trick-maker", further separation and purification of the pharmacologically active components of glycyrrhiza uralensis Fisch is in progress. It is also possible that there are various components in EGUF with synergistic and additive effects on apoptosis. Further investigation also is needed for the role of elevated intracellular $\mathrm{Ca}^{2+}$ concentration, the signal transduction pathway and the possible change of other apoptosis-related genes in the apoptotic process of MGC-803 induced by EGUF.

This research was supported by grants from Association of Science and Technology of Guangzhou (97-Z-12-01) and National New Drug Fund for Doctor (96-901-06-36).

\section{REFERENCES}

1. Agarwal R, Wang Zy, Mukhtar H. (1991) Inhibition of mouse skin tumor-initiating activity of DMBA by chronic oral feeding of glycyrrhizin in drinking water. Nutr. Cancer 15, 187-193.

2. Alnemre Es, Fernandes Tf, Haldar $\mathrm{S}$, Croce $\mathrm{Cm}$, Litwack G. (1992) Involvement of bel-2 in glucocorticoid-induced apoptosis of human pre-B-leukemias. Cancer Res. 52, 491-495.

3. Askew Ds, Ashmun Ra, Simmons Bc, Cleveland Jl. (1991) Constitutive $c-m y c$ expression in and IL-3-dependent myeloid cell line suppresses cell cycle arrest and accelerates apoptosis. Oncogene 6, 1915-1922.

4. Bhalla K, Ibrado Am, Tourkina E, Tang C, Mahoney Me, Huang Y. (1993) Taxol induces internucleosomal DNA iragmentation associated with programmed cell death in human myeloid leukemia cells. Leukemia. 7, 563-568.

5. Bissonnette Rp, Echeverri F, Mahboubi A, Green Dr. (1992) Apoptotic cell death induced by $c-m y c$ is inhibited by bcl-2. Nature 359, 552-554.

6. Chen Gq, Zhu J, Shi Xg, Ni Jh, Zhong Jh, Si Gy, Jin Xl, 
Tang W, Li Xs, Xong Sm, Shen Zx, Sun Gl, Ma J, Zhang $P$, Zhang Td, Gazin C, Naoe T, Chen Sj, Wang Zy, Chen $Z$ (1996). In vitro studies on cellular and molecular mechanisms of arsenic trioxide $\left(\mathrm{As}_{2} \mathrm{O}_{3}\right)$ in the treatment of acute promyelocytic leukemia: $\mathrm{As}_{2} \mathrm{O}_{3}$ induces $\mathrm{NB} 4$ cell apoptosis with downregulation of $\mathrm{Bcl}-2$ expression and modulation of PML-RAR alpha/PML proteins. Blood 88, 1052-1061.

7. Chen Xg, Han R. (1994) Effect of glycyrrhetinic acid on DNA damage and unscheduled DNA synthesis induced by benzo (a) pyrene. Yao Hsueh Hsueh Pao 29, 725-729.

8. Dong Y, Yang Mm, Kwan Cy. (1997) In vitro inhibition of proliferation of HL-60cells by tetrandrine and coriolus versicolor peptide derived from Chinese medicinal herbs. Life Sci. 60, 135-140.

9. Fang M, Zhang Hq, Xue Sb. (1996) Apoptosis of HL-60 cells induced by harringtonine: membrane blebs, nucleus blebs and chromatin condensation Acta Biol. Exp Sin. 29, 221-233.

10. Fesus L, Thomazy V, Falus A. (1987) Induction and activation of tissue transglutaminase during programmed cell death. FEBS Letter 224, 104-108.

11. Hickman Ja. (1992) Apoptosis induced by anticancer durgs. Cancer Metastasis Rev. 11, 121-139.

12. Kelly K. (1986) The regulation and expression of $c-m y c$ in normal and malignant cells. Annu. Rev. Immunol. 4, 317338.

13. Kerr Jfr, Wyllie Ah, Currie Ar. (1972) Apoptosis: a "Basic biological phenomenon with wide-ranging implications in tissue kinetics. Br. J. Cancer 26, 239-257.

14. Liu Y, Bhalla K, Hill C, Priest Dg. (1994) Evidence for involvement of tyrosine phosphorylation in taxol-induced apoptosis in a human ovarian tumor cell line. Biochem. Pharmacol. 8, 1265-1272.

15. Lucas M, Sanchez-margalet V. (1995) Protein kinase C involvement in apoptosis. Gen. Pharmac. 26, 881-887.

16. Masuda Y, Kawazoe N, Nakajo S, Yoshida T, Kuroiwa Y, Nakaya K. (1995) Bufalin induces apoptosis and influences the expression of apoptosis-related genes in human leukemia cells. Leuk. Res. 19, 49-556.

17. McConkey Dj, Harztell P, Jondal M, Orrenius S. (1989b) Inhibition of DNA fragmentation in thymocytes and isolated thymocyte nuclei by agents that stimulate protein kinase C. J. Biol. Chem. 264, 13399-13402.

18. Mercep M, Noguchi Pd, Ashwell Jc. (1989) The cell cycle book and lysis of an activated $\mathrm{T}$-cell hybridoma are distinct processes with different $\mathrm{Ca}^{2+}$ requirements and sensitivity to cyclosporine A. J. Immun. 142, 4085-4092.
19. Minta A, Kao Jpy, Tsien Ry. (1989) Fluorescent indicators for cytosolic calcium based on rhodamine and fluorescein chromophores. J. Biol. Chem. 264, 8171-8178.

20. Nicotera P, Orrenius S. (1998) The role of calcium in apoptosis. Cell Calcium 23, 173-180.

21. Schwartz Lm, Jones Mee, Kosz L, Kuah K. (1993) Selective repression of actin and myosin heavy chain expression during the programmed death of insect skeletal muscle. Dev. Biol. 158, 448-455.

22. Shi Gz. (1992) Blockage of glyrrhiza uralensis and chelidonium majus in MNNG induced cancer and mutagenesis. Chung Hua Yu Fang I Hsueh Tsa Chih 26, $165-167$.

23. Smegne Rj, Vendrell M, Hayward M, Bader Sj, Miao Gg, schilling K, Robertson Lm, Curran T, Morgan Ji. (1993) Continuous $c$-fos expression precedes programmed cell death in vitro. Nature 263, 166-169.

24. Smith J, Williams Gt, Kingston R, Jenkinson Ej, Owen Jjt. (1989) Antibodies to CD3/T-cell receptor complex induce death by apoptosis in immature $\mathrm{T}$ cells in thymic cultures. Nature (Lond.) 337, 181-184.

25. Squier Mkt, Miller Ack, Malkinson Am, Cohen $\mathrm{Jj}$. (1994) Calpain activation in apoptosis. J. Cell Physiol. 159, 229-237.

26. Tanizawa A, Fujimori A, Fujimori Y, Pommier Y. (1994) Comparison of topoisomerase I inhibition, DNA damage, and cytotoxicity of camptothecin derivatives presently in clinical trials. J. Natl. Cancer Inst. 86, 836-842.

27. Tomei Dl, Kanter P, Wenner Ce. (1988) Inhibition of radiation-produced apoptosis in vitro by tumor promoters. Bilchem. Biophys. Res. Commun. 155, 324-331.

28. Wang Zy, Agarwal R, Khan Wa, Mukhtar H. (1992) Protection against benzo [a] pyrene- and $N$ nitrosodiethylamine-induced lung and forestomach tumorigenesis in $\mathrm{A} / \mathrm{J}$ mice by water extracts of green tea and licorice. Carcinogenesis 13, 1491-1494.

29. Xiong Cy, Zhang Zz. (1999) Apoptosis. Chin. Bull. Life Sci. 11 supplement: $37-41$.

30. Zhang Gq, Ren Rg, Kong Qy, Li Yj, Guan Wm. (1997) Effects of radix salivas miltiorrhizae on proliferation, apoptosis and c-myc protein expression of fibroblast in culture of kidney with lupus nephritis. Chin. J. Integ. Trad. West. Medi. 17, 473-475.

31. Zhang X, Yang Xp, Pan Qc. (1998) Studies on the anticancer effect and apoptosis induction in human liver cancer cell line (BEL-7402) by sodium artesunate. Chin. J. Herb. Drugs 29, 467-469. 